\title{
Neuronal Matrix Metalloproteinase-2 Degrades and Inactivates a Neurite-Inhibiting Chondroitin Sulfate Proteoglycan
}

\author{
Jian Zuo, ${ }^{1}$ Toby A. Ferguson, ${ }^{1}$ Yosbani J. Hernandez, ${ }^{1}$ William G. Stetler-Stevenson, ${ }^{2}$ and David Muir ${ }^{1}$ \\ ${ }^{1}$ Departments of Pediatrics (Neurology Division) and Neuroscience, University of Florida Brain Institute and College of \\ Medicine, Gainesville, Florida 32610-0296, and 2Extracellular Matrix Pathology Section, Laboratory of Pathology, \\ National Cancer Institute, National Institutes of Health, Bethesda, Maryland 20892
}

\begin{abstract}
Chondroitin sulfate proteoglycans (CSPGs) are implicated in the regulation of axonal growth. We previously reported that the neurite-promoting activity of laminin is inhibited by association with a Schwann cell-derived CSPG and that endoneurial laminin may be inhibited by this CSPG as well [Zuo J, Hernandez YJ, Muir D (1998) Chondroitin sulfate proteoglycan with neuriteinhibiting activity is upregulated after peripheral nerve injury. $\mathrm{J}$ Neurobiol 34:41-54]. Mechanisms regulating axonal growth were studied by using an in vitro bioassay in which regenerating embryonic dorsal root ganglionic neurons (DRGn) were grown on sections of normal adult nerve. DRGn achieved slow neuritic growth on sections of normal nerve, which was reduced significantly by treatment with metalloproteinase inhibitors. Similar results were obtained on a synthetic substratum composed of laminin and inhibitory CSPG. DRGn expressed the matrix metalloproteinase, MMP-2, which was transported to the growth
\end{abstract}

Injury to mammalian peripheral nerve is followed by Wallerian degeneration in the distal nerve segment, which involves the clearing of severed axons and myelin. Despite this extensive remodeling, the primary structure of endoneurial basal laminae persists, providing an essential scaffolding for nerve regeneration (Satinsky et al., 1964; Ide et al., 1983). However, modifications to the molecular composition of the basal lamina occur that, as part of the degenerative process, appear to be a prerequisite for axonal regeneration (Salonen et al., 1987; Giannini and Dyck, 1990; Fu and Gordon, 1997). Using a series of nerve anastomoses, Langley and Anderson (1904) reported that transected axons do not regenerate along a normal nerve. More recently, the nonpermissive status of normal nerve was confirmed by Bedi and coworkers (1992), who found that adult sensory axons fail to grow neurites on sections of normal adult nerve. These findings suggest that, although rich in molecules that promote axonal regeneration in vitro, Schwann cell surfaces and their associated basal lamina in normal nerve fail to support axonal growth.

It is now generally accepted that extracellular matrices (ECM) of the mammalian nervous system can present to neurons both stimulatory and inhibitory cues for axonal growth. Recent studies of nonpermissive nervous tissues show that several families of cell surface and ECM macromolecules have potential growth inhibi-

\footnotetext{
Received April 8, 1998; accepted April 30, 1998.

Support was provided by grants awarded to D.M. from the National Institutes of Health (NS31255) and the Florida State Brain and Spinal Cord Injury Rehabilitation Trust Fund. We thank Dr. R. E. Galardy for the gift of GM6001.

Correspondence should be addressed to Dr. David Muir, Pediatric Neurology, Box 100296, University of Florida College of Medicine, Gainesville, FL 32610. Copyright (C) 1998 Society for Neuroscience $0270-6474 / 98 / 185203-09 \$ 05.00 / 0$
}

cone. Recombinant MMP-2 inactivated the neurite-inhibiting CSPG without hindering the neurite-promoting potential of laminin. Similarly, neuritic growth by DRGn cultured on normal nerve sections was increased markedly by first treating the nerve sections with MMP-2. The proteolytic deinhibition by MMP-2 was equivalent to and nonadditive with that achieved by chondroitinase, suggesting that both enzymes inactivated inhibitory CSPG. Additionally, the increases in neuritic growth resulting from treating nerve sections with MMP-2 or chondroitinase were blocked by anti-laminin antibodies. From these results we conclude that MMP-2 provides a mechanism for the deinhibition of laminin in the endoneurial basal lamina and may play an important role in the regeneration of peripheral nerve.

Key words: chondroitin sulfate proteoglycan; matrix metalloproteinase; neuronal regeneration; neurite inhibitor; basal lamina; peripheral nerve; laminin; cryoculture tory properties (for review, see Faissner and Steindler, 1995; Kolodkin, 1996). In particular, chondroitin sulfate proteoglycans (CSPGs) are abundant in the adult nervous system and evoke a strong avoidance reaction by a variety of neuronal subtypes in vitro (Muir et al., 1989a; Snow et al., 1991). CSPGs permeate boundary structures confronted by developing and regenerating axons (Oakley and Tosney, 1991; Brittis et al., 1992; Pindzola et al., 1993). Normal adult peripheral nerve contains neuriteinhibiting activity associated with CSPG, which is increased further in the distal nerve after injury (Zuo et al., 1998). CSPG colocalizes with laminin within the Schwann cell basal lamina and appears to have a wider distribution within the endoneurial compartment in degenerating nerve (Kuecherer-Ehret et al., 1990; Tona et al., 1993). Because of its considerable regenerative capacity, it may seem counter-intuitive that peripheral nerve contains neurite inhibitors. One possibility is that growth inhibitors help to stabilize axons in normal nerve. By blocking the neurite-promoting potential of laminin in the endoneurial basal lamina, inhibitory CSPG may prevent axons from sprouting collaterals, especially at nodes of Ranvier. This implies that nerve sheaths actually might suppress axonal growth under normal conditions. However, this suppression somehow must be reversed in nerve regeneration.

The growth cone, the leading structure of growing axons, senses guidance cues from the surrounding environment and implements directed outgrowth. Axonal regeneration requires extensive growth cone motility and infiltration within damaged and degenerating nervous tissue. Substantial evidence now indicates that neurons secrete matrix-degrading enzymes and actively 
remodel surrounding ECM substrata (Monard, 1988; Pittman and Buettner, 1989; Fambrough et al., 1996). Proteinases, including plasminogen activators and matrix metalloproteinases (MMPs), are expressed by peripheral neurons and released by growth cones, implicating the growing tip of axons in the proteolysis of matrix components (Pittman and Williams, 1988; McGuire and Seeds, 1990; Muir, 1994; Nordstrom et al., 1995; Hayden and Seeds, 1996). MMPs are believed to be the physiologically relevant mediators of ECM degradation and matrix remodeling (Matrisian, 1992). MMPs also participate in the proteolytic processing of both ECM and cell surface components, which can result in alterations of cell properties such as attachment and migration (Chantry et al., 1992; DiStefano et al., 1993; Ray and StetlerStevenson, 1995; Giannelli et al., 1997). Thus, the function of MMPs, at first thought to be limited to the catabolism and cellular infiltration of ECM, also includes an important regulatory mechanism for the proteolytic activation of cryptic molecular domains.

In the present report, axonal growth by regenerating embryonic dorsal root ganglionic neurons (DRGn) cultured on sections of normal adult nerve and on a synthetic substratum composed of laminin and inhibitory CSPG was found to be dependent on metalloproteinase activity. DRGn expressed MMP-2, which inactivated inhibitory CSPG and unmasked the neurite-promoting activity of associated laminin. From these studies we conclude that MMP-2 provides a mechanism for the deinhibition of laminin in the endoneurial basal lamina.

\section{MATERIALS AND METHODS}

Assay of neuritic growth. Dorsal root ganglia from day 8 chick embryos were dissociated enzymatically, and the DRGn were purified by differential cell attachment as described (Manthorpe et al., 1983; Muir et al., 1989b). Assays of neurite outgrowth and inhibition were performed as reported previously (Muir et al., 1989a; Zuo et al., 1998). Briefly, substrata were established by treating polyornithine-coated 96-well plates with of a maximally stimulating concentration of EHS tumor laminin-1 $(1-2 \mu \mathrm{g} / \mathrm{ml}, 50 \mu \mathrm{l} /$ well) premixed with the neurite-inhibiting CSPG, NIF, at the concentrations indicated. DRGn were seeded $\left(10^{3}\right.$ neurons per well) in a defined medium containing N2 supplements, $1 \%$ heattreated bovine serum albumin, and $10 \mathrm{ng} / \mathrm{ml}$ nerve growth factor (DMEM/N2+NGF). DMEM/N2 is a modification of the defined medium N2 of Bottenstein and Sato (1979) in which the base medium is replaced with DMEM only. It was shown previously that cysteine (a common component of classical media) is a potent inhibitor of metalloproteinases (Muir, 1994). Recent formulations of DMEM (Life Technologies, Grand Island, NY) have replaced cysteine with cystine (dicysteine), which does not inhibit metalloproteinases. Neurite outgrowth was scored by phasecontrast microscopy after $4 \mathrm{hr}$ by counting the percentage of neurons bearing processes $>4$ cell body diameters. Under these conditions the maximal neuritic response to laminin was $\approx 75 \%$ of neurons bearing neurites. For the assay of inhibitory activity, we defined one neurite inhibitory unit (NIU) as the sample concentration required to reduce growth to $50 \%$ of the maximal response to laminin. Approximately $75 \%$ inhibition of laminin activity was achieved by $2 \mathrm{NIU} / \mathrm{ml}$ of inhibitory CSPG (see below) and maximal inhibition (96\%) by $>4 \mathrm{NIU} / \mathrm{ml}$ in these assays. The high buoyant density inhibitory CSPG, designated neuriteinhibiting factor (NIF), used in this study was isolated from RN22 rat schwannoma conditioned medium as described previously (Muir et al., 1989a). Inhibitory CSPG with similar properties was obtained from Schwann cell medium and from rat nerve (Zuo et al., 1998). RN22 are a more abundant source than Schwann cells, and the nerve preparation may contain CSPG contaminants contributed by cells other than Schwann cells. Also, metabolic radiolabeling was most effective in cell culture. Therefore, RN22-derived NIF was chosen for use in this study.

Neurite assays also were used to test for proteolytic inactivation of NIF, either when in solution or when substratum-bound with laminin. NIF was incubated in appropriate buffers with active forms (see below) of recombinant MMP-2 $(2 \mu \mathrm{g} / \mathrm{ml})$, recombinant MMP-3 $(2 \mu \mathrm{g} / \mathrm{ml})$, or chondroitinase $\operatorname{ABC}(0.1 \mathrm{U} / \mathrm{ml})$ (Sigma, St. Louis, MO). Recombinant human proMMP-2 was prepared as described elsewhere (Fridman et al., 1992). Recombinant rat proMMP-3 (Machida et al., 1989) was a gift from Dr. G. Ciment (Oregon Health Science University). For all applications, recombinant proMMP-2 and proMMP-3 were activated by treatment with $1 \mathrm{~mm} p$-aminophenylmercuric acetate at $37^{\circ} \mathrm{C}$ for $2 \mathrm{hr}$ and then dialyzed against $50 \mathrm{~mm}$ Tris-HCl, $\mathrm{pH}$ 7.8. The protease inhibitor phenanthroline initially was dissolved at $0.5 \mathrm{M}$ in $50 \%$ ethanol and used at a final concentration of $1 \mathrm{~mm}$.

Cryoculture assay. Cryoculture is a neurite outgrowth assay in which neurons are cultured directly on unfixed nerve sections (Carbonetto et al., 1987). Rat sciatic nerves were removed under general anesthesia and rapidly frozen in dry ice. Nerve segments $(1 \mathrm{~cm})$ were cryosectioned $(14 \mu \mathrm{m})$ and then mounted on sterile polyornithine-coated glass coverslips and stored at $-20^{\circ} \mathrm{C}$. Before cryoculture, mounted sections were treated for $4 \mathrm{hr}$ at $37^{\circ} \mathrm{C}$ with (1) activated MMP-2 $(10 \mu \mathrm{g} / \mathrm{ml})$ in $25 \mathrm{mM}$ Tris-HCl, pH 7.8, containing $2.5 \mathrm{mM} \mathrm{CaCl}_{2} ;$ (2) chondroitinase $\mathrm{ABC}$ $(0.1 \mathrm{U} / \mathrm{ml})$ (Sigma) in $50 \mathrm{~mm}$ Tris-HCl, pH 8.0, containing $50 \mathrm{~mm} \mathrm{NaCl}$; or (3) buffer control. DRGn (4000/section) were seeded directly onto the nerve sections in DMEM/N2 ${ }^{+\mathrm{NGF}}$. As indicated, the metalloproteinase inhibitors cysteine $(250 \mu \mathrm{M})$ and 3 -( $N$-hydroxycarbamoyl)-2(R)isobutylpropionyl-L-tryptophan methylamide (GM6001; $50 \mu \mathrm{M})$ (prepared as described by Grobelny et al., 1992) were added to the culture medium. Assays also were performed by using function-blocking antibodies to laminin. Antibodies were added to the culture medium $1 \mathrm{hr}$ after the DRGn were first seeded to allow for attachment to the nerve sections. Polyclonal antibody raised against human placental laminins (Telios Pharmaceuticals, La Jolla, CA) was used at a 1:50 dilution. This polyclonal antibody cross-reacts with and blocks the neurite-promoting activity of rat laminin-1 and laminin-2 (Engvall et al., 1986). Normal rabbit serum was used as a control for this polyclonal laminin antibody.

At $48 \mathrm{hr}$ after seeding DRGn, assays were terminated by fixing the cryoculture sections with $4 \%$ paraformaldehyde in $0.1 \mathrm{M}$ phosphate buffer. Chick neurons were immunolabeled selectively with monoclonal anti-chick neural cell adhesion molecule (N-CAM) (Watanabe et al., 1986), using biotinylated anti-mouse IgG and extravidin-FITC conjugate (Sigma). Immunolabeled neurites were viewed by epifluorescence microscopy, and lengths were scored in acquired digital images. The hybridoma cell line $5 \mathrm{e}$, producing monoclonal N-CAM antibody, was obtained from the Developmental Studies Hybridoma Bank (University of Iowa; National Institute of Child Health and Human Development contract NO1-HD-2-3144). The 5e cell line was grown in medium supplemented with IgG-depleted fetal bovine serum $(2 \%)$ and OptiMAB (Life Technologies). Anti-chick N-CAM antibody was isolated from culture supernatant by protein-G affinity chromatography and used at $10 \mu \mathrm{g} / \mathrm{ml}$.

Degradation of radiosulfate-labeled inhibitory CSPG. $\left[{ }^{35} \mathrm{~S}\right] \mathrm{NIF}$ was prepared by metabolic labeling of RN22 cultures and isolated from conditioned medium as described previously (Muir et al., 1989a). [ ${ }^{35}$ S]NIF was incubated with MMP-2 and chondroitinase ABC as described above for bioassays. For SDS-PAGE, samples were prepared under highly reducing and denaturing conditions (Lowe-Krentz and Keller, 1984) and electrophoresed on $5 \%$ polyacrylamide minigels. Autoradiographic gels were dried, coated with scintillant (EnHance, New England Nuclear, Boston, MA), and exposed to x-ray film for $7 \mathrm{~d}$ before automated development.

\section{RESULTS}

\section{Metalloproteinase-dependent neurite outgrowth on reconstituted NIF-laminin substrata}

NIF is a CSPG first isolated from RN22 schwannoma culture medium that inhibits the neurite-promoting activity of laminin in a concentration-dependent manner (Muir et al., 1989a). We first reported that the inhibition of neuritic growth on a laminin substratum treated with a maximally inhibiting concentration of $\mathrm{NIF}$ (8 NIU/ml) was persistent and nearly complete. In later work we found that free cysteine (a common component of culture media) is a potent inhibitor of metalloproteinase activity and that levels of cysteine in many classical culture media significantly inhibited metalloproteinase activity in vitro (Muir, 1994). In the present study a defined culture medium (DMEM/ $\mathrm{N} 2{ }^{+\mathrm{NGF}}$ ) was formulated without cysteine to minimize metalloproteinase inhibition (see Materials and Methods). All DRGn 


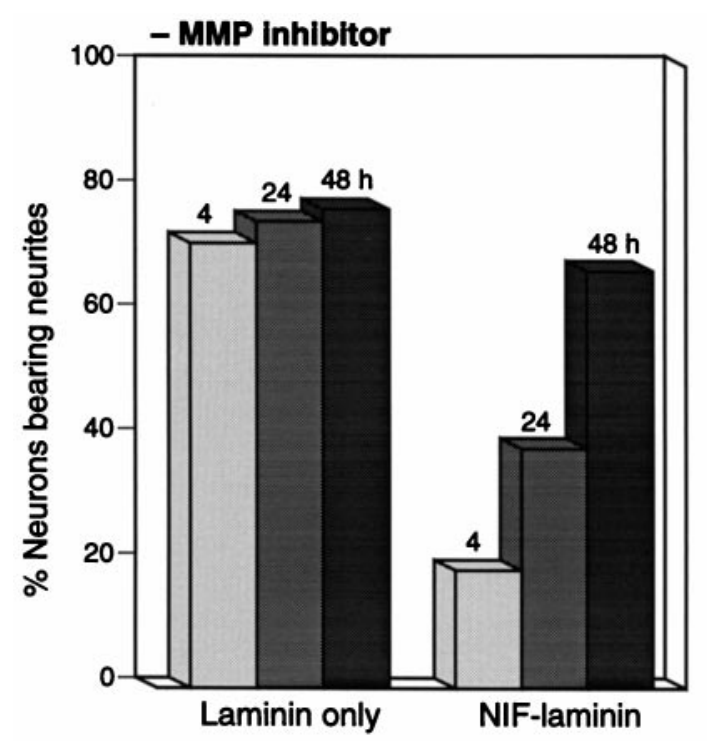

bioassays included NGF in the culture medium. In a standard $4 \mathrm{hr}$ bioassay, neuritic growth on a NIF-laminin substratum was virtually the same with or without cysteine in the medium. However, in the absence of cysteine, gradual neuritic growth was observed on NIF-laminin that was not seen previously by neurons grown in the presence of cysteine. To quantitate this effect, we established a NIF-laminin substratum, using a submaximal concentration of NIF (2 NIU/ml) and a maximal concentration of laminin $(1 \mu \mathrm{g} / \mathrm{ml})$. On this substratum $19 \%$ of the DRGn had extended neurites ( $\geq 4$ cell body diameters) after $4 \mathrm{hr}$ in medium with and without cysteine. This response corresponded to $\sim 75 \%$ inhibition of the neurite outgrowth on laminin only. Results are shown in Figure 1. Over $48 \mathrm{hr}$, neuritic growth on this NIFlaminin substratum steadily increased to $67 \%$ in the absence of cysteine but remained mainly inhibited in the presence of cysteine. Cysteine did not alter the neuritic growth on laminin alone (Fig. 1). These results suggest that the time-dependent neuritic growth observed on NIF-laminin was dependent on a metalloproteinase activity. On the basis of this initial observation, we hypothesized that DRGn express a metalloproteinase that inactivates the inhibitory proteoglycan NIF and, as a result, that unmasks the neurite-promoting potential of NIF-inhibited laminin. We refer to this effect as deinhibition.

\section{Metalloproteinase-dependent neurite outgrowth on nerve sections}

In the culture assays described above, inhibited substrata were established by the recombination of laminin-1 (isolated from mouse EHS tumor) and RN22-derived NIF. An apparently identical inhibitory CSPG was isolated from cultured rat Schwann cells and normal adult rat nerve (Zuo et al., 1998). In addition, we reported findings indicating that the neurite-promoting activity of laminin in the endoneurial basal lamina of adult nerve is inhibited by association with this CSPG. In the nerve, laminin-rich basal laminae form continuous sleeves around axon-Schwann cell units that appear in longitudinal section as an array of parallel tracks. Embryonic neurons grown on fresh-frozen nerve sections extend neurites along these basal lamina tracks. This growth pattern clearly demonstrates that neurites probe for and follow neuritepromoting or, at least, permissive pathways within the tissue section substratum. Adult DRGn fail to extend neurites on sections of normal adult nerve (Bedi et al., 1992); therefore, in the
Table 1. Neuritic growth on nerve sections treated with CSPGdegrading enzymes

\begin{tabular}{lll} 
Treatment & Neurite length $(\mu \mathrm{m})$ & Increase $(\%)$ \\
\hline Control & $119.7 \pm 41.0$ & \\
MMP-2 & $179.7 \pm 60.6^{*}$ & 50 \\
Ch'ase & $183.5 \pm 45.0^{*}$ & 53
\end{tabular}

Embryonic chick DRGn were cultured on fresh-frozen sections of normal adult rat sciatic nerve pretreated with buffer only (Control), MMP-2, or chondroitinase ABC (Ch'ase), as described in Materials and Methods. DRGn were grown on nerve sections in DMEM/N2 ${ }^{+\mathrm{NGF}}$ medium for $48 \mathrm{hr}$, and the assay was terminated by aldehyde fixation. The chick DRGn were immunolabeled with an anti-chick N-CAM monoclonal antibody, and the length of the single longest neurite per neuron was measured. In random fields, $>50$ neurons were scored on multiple sections in three experiments. Data represent the means \pm SD. Statistical significance was determined by Student's $t$ test. ${ }^{*} p<0.0001$.

present study embryonic DRGn were used to examine the inhibitory properties of this tissue.

Neuritic growth by embryonic DRGn on normal nerve sections was gradual $(\approx 120 \mu \mathrm{m} / 48 \mathrm{hr}$ ) (see Table 1 ; Fig. $4 A$ ) and was more reminiscent of the long-term growth observed on a NIF-laminin substratum (as described in Fig. 1) than growth on laminin alone (which exceeded $1000 \mu \mathrm{m} / 48 \mathrm{hr}$ ). Furthermore, neurite outgrowth on nerve sections was decreased by cysteine, also like that on a reconstituted NIF-laminin substratum. To avoid potential toxicity at higher cysteine levels and to improve the specificity of metalloproteinase inhibition, we used the dipeptide metalloproteinase inhibitor GM6001 in subsequent cryoculture assays. The addition of GM6001 to the culture medium decreased neuritic growth in a concentration-dependent manner over the range of 1-100 $\mu \mathrm{M}$. Compared with controls, the average neurite length in a $48 \mathrm{hr}$ assay was decreased to $32.0 \pm 37.5$ by a near-maximal concentration of GM6001 (50 $\mu \mathrm{M})$ (ANOVA; $p<0.0001)$. GM6001 has very low toxicity, and neuritic growth on laminincoated plastic was unaffected by concentrations several-fold higher. From these results we conclude that neuritic growth by embryonic DRGn on normal adult nerve sections involves a metalloproteinase activity.

\section{Regenerating DRGn express and transport MMP-2}

We previously reported zymographic (gelatin overlay electrophoresis) and Western immunoblot analyses demonstrating that 

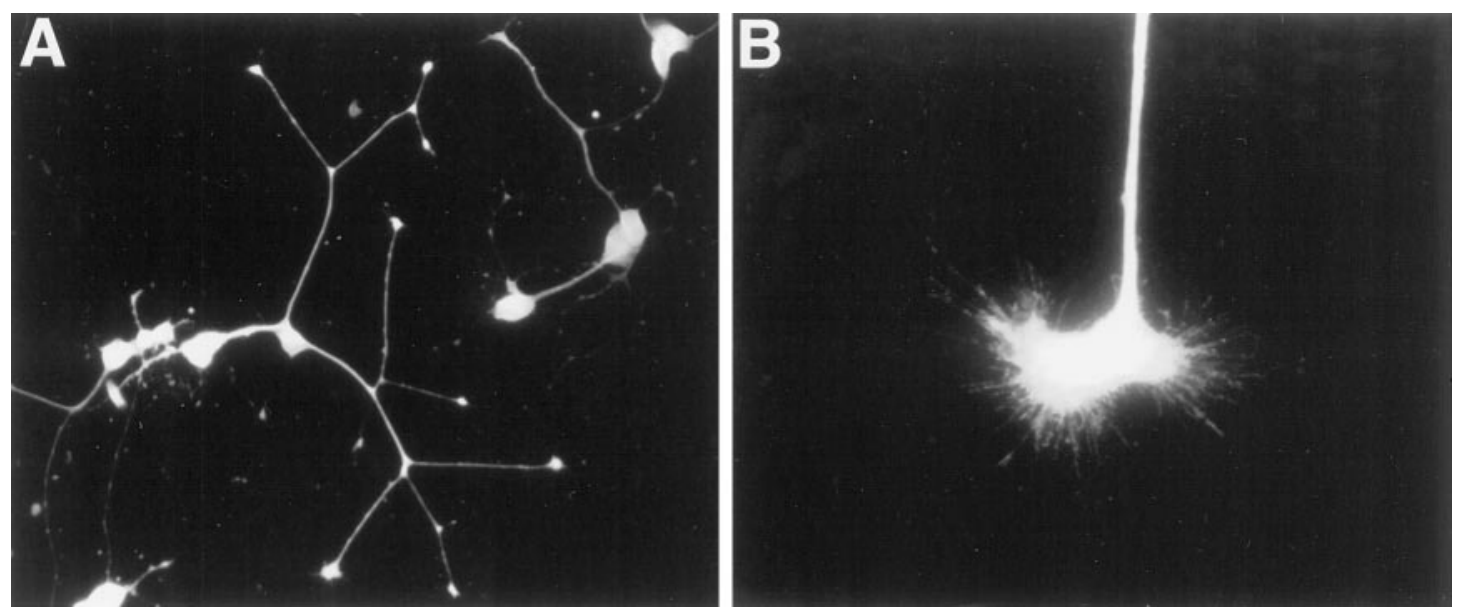

Figure 2. Immunofluorescent microscopy of cultured DRGn $(A)$ and a selected growth cone labeled with MMP-2 antibody $(B)$. DRGn were grown for $24 \mathrm{hr}$ on laminin-coated chamber slides and then immunolabeled with anti-MMP2/475 antibody $(2 \mu \mathrm{g} / \mathrm{ml})$ and FITC-conjugated anti-rabbit secondary antibody.

MMP-2 is the predominant MMP secreted by DRGn cultures grown in the presence of NGF (Muir, 1994). To support the contention that MMP-2 played a role in deinhibiting substrata in the assays above, we examined whether MMP-2 was present at the growing tip of neurites. Immunocytochemical labeling of permeabilized DRGn cultures showed that MMP-2 was present within neuronal cell bodies, neurites, and growth cones, including filopodia (Fig. $2 A, B$ ). Staining of unpermeabilized neurons indicated that MMP-2 also might be present on the cell surface (data not shown). Low contrast and the uncertainty that fine growth cone membranes remained impervious to antibodies made it difficult to determine the distribution of MMP-2 on the surface of the growing tip. DRGn cultures contain a variety of sensory neuron subtypes; however, the vast majority of DRGn grown in the presence of NGF was intensely MMP-2-positive. MMP-2 expression by DRGn cultured on different substrata (including NIF-laminin) was not noticeably different. These results show that MMP-2 is transported to the growth cone of DRGn during in vitro regeneration.

\section{Recombinant MMP-2 inactivates NIF and deinhibits NIF-laminin substrata}

Incubating NIF with concentrated medium collected from DRGn cultures resulted in a nearly complete loss of the inhibitory activity of NIF, that is, its ability to inhibit the neurite-promoting activity of laminin (data not shown). To confirm the effect of MMP-2 on NIF activity, we incubated NIF with various concentrations of recombinant MMP-2 and then assayed for neurite-inhibiting activity. Because MMP-3 is expressed by $\mathrm{PC} 12$ cells treated with NGF and by certain embryonic neurons in vivo (Machida et al., 1989; Nordstrom et al., 1995), the effects of MMP-3 on NIF activity were examined also. Treatment with MMP-2 decreased NIF activity in a concentration-dependent manner (Fig. 3A). By comparison, MMP-3 was much less potent, and only a partial loss of NIF activity was observed even at high concentrations of activated enzyme. This finding was somewhat surprising because MMP-3 is known to degrade a variety of proteoglycans and to have a broader substrate specificity than MMP-2 (Wilhelm et al., 1987). However, these results indicate that NIF activity is particularly vulnerable to proteolytic inactivation by MMP-2.

In the experiments above, NIF was inactivated by MMP-2 before recombination with laminin and application to the culture substratum. We also examined the ability of MMP-2 to alter the neurite-promoting properties of a NIF-laminin substratum already established on tissue culture plastic. Results are given in Figure $3 B$. Treatment of a maximally inhibited NIF-laminin substratum with nanomolar concentrations of MMP-2 inactivated $\mathrm{NIF}$ and restored the neurite-promoting activity of the laminin component. This deinhibition by MMP-2 did not occur in the presence of the metalloproteinase inhibitor phenanthroline. Thus, MMP-2 proteolytic activity inactivated NIF without hindering the neurite-promoting activity of laminin. Treatment of laminin-1 and laminin-2 (when in solution or when substratumbound) with MMP-2 or MMP-3 neither increased nor decreased their neurite-promoting activity.

\section{MMP-2 deinhibits nerve sections in cryoculture assay}

Embryonic DRGn cultured on nerve sections extended neurites along exposed basal laminae with an average length of $120 \mu \mathrm{m}$ in a $2 \mathrm{~d}$ period (Table 1; Fig. 4A). To examine if modification of the nerve substratum by MMP-2 influenced neuritic growth, we pretreated sections with recombinant MMP-2 before cryoculture. Pretreatment with MMP-2 resulted in a 50\% increase in neurite outgrowth by DRGn (Table 1; Fig. 4B). Neurite growth continued to be closely associated with the basal lamina in sections treated with MMP-2, indicating that MMP-2 deinhibited the basal lamina of normal nerve. In addition, neuritic growth was increased to a similar extent on nerve sections treated with chondroitinase ABC (Table 1). The sequential treatment of nerve sections with MMP-2 and chondroitinase did not have a significant additive effect over treatment with either enzyme alone. These results, combined with the substrate specificity of chondroitinase, strengthen the likelihood that both chondroitinase and MMP-2 degraded the same inhibitory component, a CSPG. It is important to note that NIF activity is expressed only by the intact CSPG and that NIF can be inactivated by degradation of either its chondroitin sulfate chains or its core protein (Muir et al., 1989a).

\section{The neurite-promoting activity of laminin is deinhibited by treatment of nerve sections with MMP-2 or chondroitinase}

Several groups have reported that neuritic growth on normal nerve sections is not inhibited by antibodies that block laminin function (Sandrock and Matthew, 1987; Anton et al., 1994; Agius 

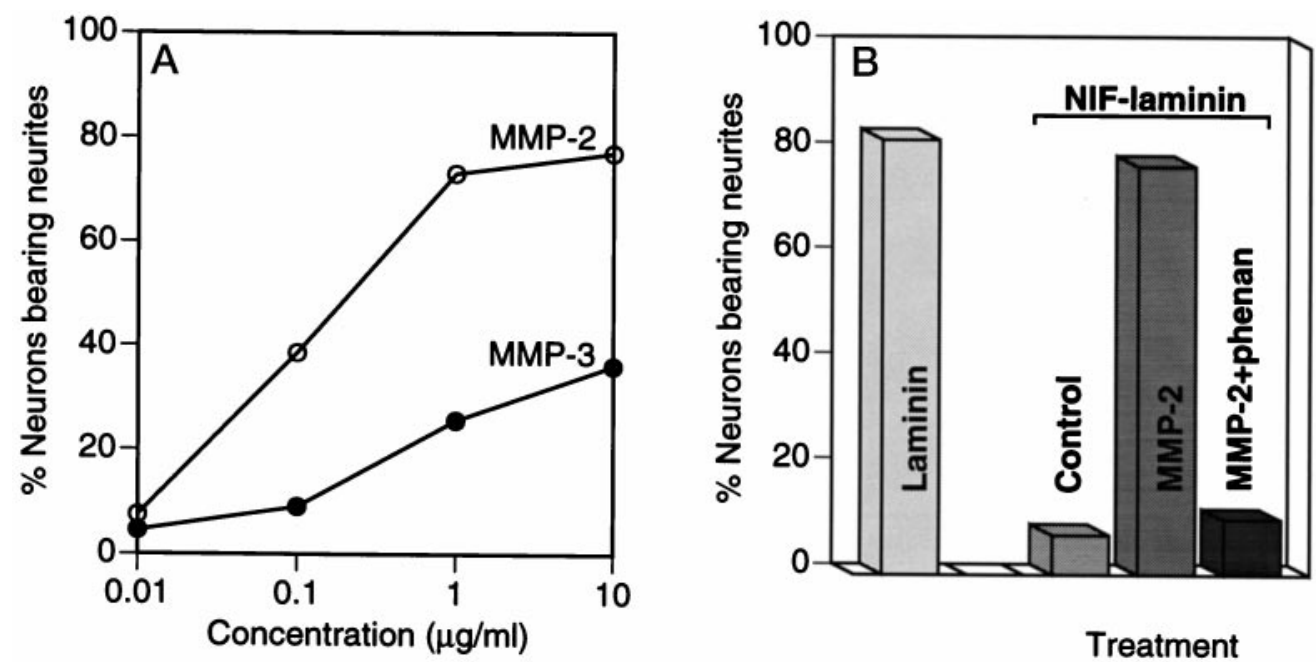

Figure 3. Treatment of NIF with MMP-2 caused a concentration-dependent loss of neurite-inhibiting activity. $A$, NIF was incubated first with serial concentrations $(0.01-10 \mu \mathrm{g} / \mathrm{ml})$ of recombinant human MMP-2 or MMP-3. The equivalent of $8 \mathrm{NIU} / \mathrm{ml}$ of NIF (a near-maximal concentration before MMP treatment) was mixed with laminin $(2 \mu \mathrm{g} / \mathrm{ml})$, and then the mixture was applied $(50 \mu \mathrm{l} /$ well) to culture 96 -well plates coated with polyornithine. The control condition consisted of $8 \mathrm{NIU} / \mathrm{ml}$ of untreated (fully active) NIF mixed with laminin $(2 \mu \mathrm{g} / \mathrm{ml})$. $B$, NIF ( 8 NIU/ml) was mixed with laminin $(2 \mu \mathrm{g} / \mathrm{ml})$ and applied to culture wells, forming a highly inhibitory substratum (Control). Then this substratum was treated with MMP-2 (2 $\mu \mathrm{g} / \mathrm{ml})$, with the inclusion of the MMP inhibitor phenanthroline as indicated. For both $A$ and $B$, neurons were seeded on the resulting substrata, and 4 hr later the percentage of neurons bearing a neurite $>4$ cell body diameters was scored. Determinations were made by scoring 50 neurons per culture well, and data represent the means of duplicate determinations made in each of two independent assays $(n=4) . A, \mathrm{SD} \leq 4.4 ; B, \mathrm{SD} \leq 5.0$.
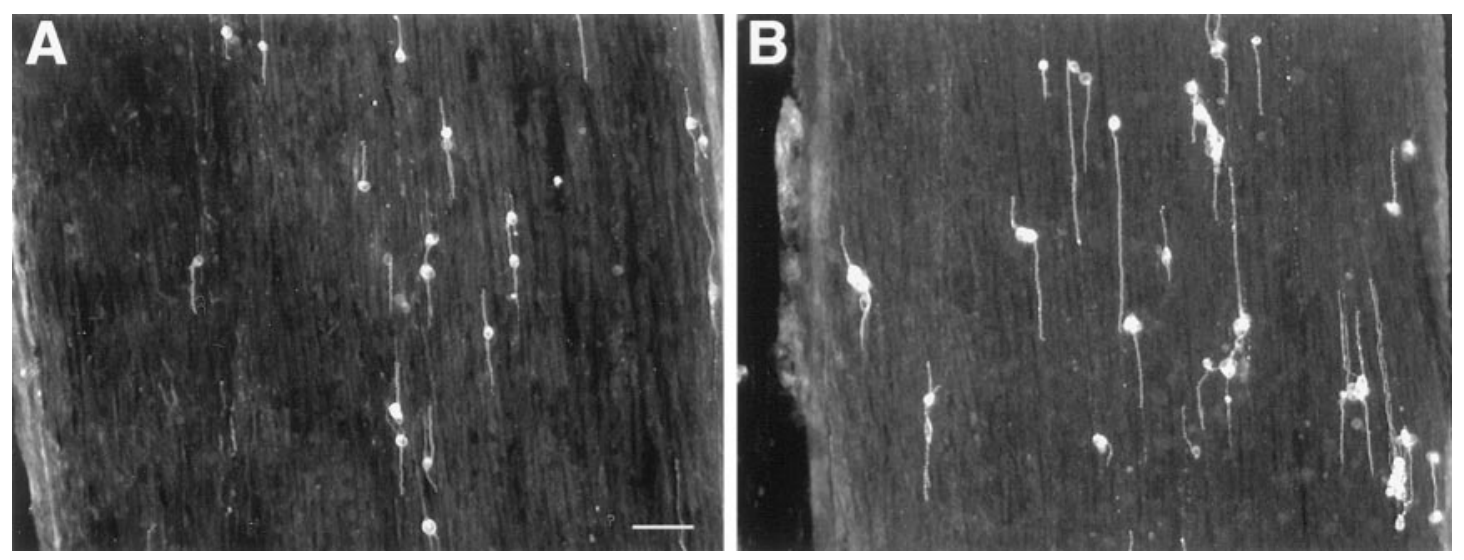

Figure 4. Neuronal cryoculture on peripheral nerve treated with MMP-2. Shown is a $2 \mathrm{~d}$ neuritic growth by embryonic chick DRGn cultured on fresh-frozen sections of adult rat sciatic nerve. Neurites follow the longitudinal paths of exposed basal laminae. In the control condition $(A)$, the DRGn were cultured on (untreated) fresh-frozen sections of normal adult rat sciatic nerve in DMEM/N2 ${ }^{+\mathrm{NGF}}$ medium. In $B$, nerve sections were pretreated with MMP-2 $(10 \mu \mathrm{g} / \mathrm{ml})$ before the seeding of the neurons. Chick neurons were labeled immunofluorescently, using a species-specific monoclonal antibody to N-CAM, and images were captured by digital microphotography. Scale bar, $100 \mu \mathrm{m}$.

and Cochard, 1998). This finding indicates that the baseline neuritic growth on nerve sections is not mediated by laminin and that laminin present in normal nerve is not functionally active. Our aim was to determine whether the increases in neuritic growth seen on normal nerve treated with MMP-2 and chondroitinase occurred in response to laminin. Cryoculture experiments on enzyme-treated sections were performed in the presence of antibodies that block neuritic growth in response to laminin. Neuritic growth was increased slightly on nerve sections in the presence of normal rabbit serum, which served as a baseline control for the antibody conditions (Fig. 5). Neuritic growth on sections was increased by $\sim 50 \%$ on sections deinhibited with either MMP-2 or chondroitinase, and this effect was reduced to baseline in the presence of the laminin antibodies. From these results we conclude that MMP-2 and chondroitinase deinhibit the neurite-promoting activity of endoneurial laminin.

\section{Proteolytic degradation of NIF core protein}

To confirm the proteolytic degradation of NIF by MMP-2, we treated $\left[{ }^{35} \mathrm{~S}\right] \mathrm{NIF}$ with recombinant MMP-2 and then examined it by gel electrophoresis (Fig. 6). [ $\left.{ }^{35} \mathrm{~S}\right] \mathrm{NIF}$ was prepared by metabolic labeling of its chondroitin sulfate chains by the inclusion of inorganic radiosulfate in the RN22 culture medium (see Materials and Methods). Intact $\left[{ }^{35} \mathrm{~S}\right] \mathrm{NIF}$ appeared on autoradiographic gels as a broad band with a molecular mass of $\approx 400 \mathrm{kDa}$ (lane 1). After incubation with MMP-2, the $400 \mathrm{kDa}$ autoradiographic band was shifted and included a trail of ${ }^{35} \mathrm{~S}$-labeled polypeptides (lane 2). NIF degradation by MMP-2 was prevented in the 


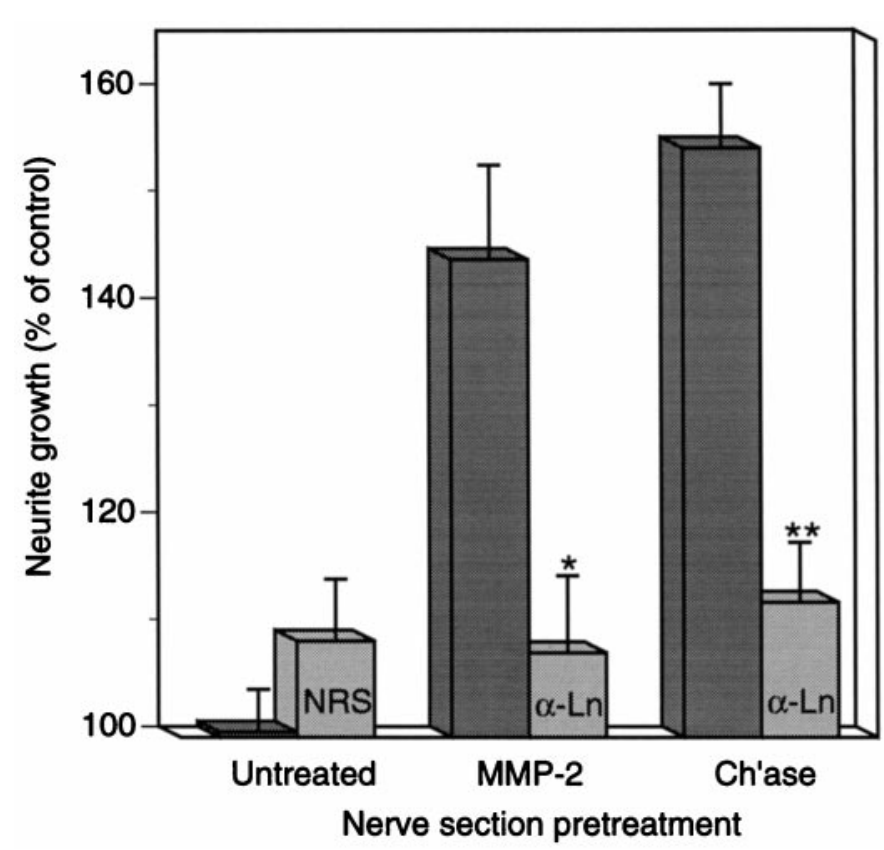

Figure 5. Embryonic chick DRGn were cultured on fresh-frozen sections of normal adult rat sciatic nerve pretreated with buffer only (Untreated, control), MMP-2, or chondroitinase ABC (Ch'ase), as described in Materials and Methods. DRGn were seeded on the nerve sections and allowed to attach for $1 \mathrm{hr}$ before treatment with normal rabbit serum (NRS, control) or anti-laminin antibodies $(\alpha-L n)$. Assays were terminated after $48 \mathrm{hr}$ of growth by aldehyde fixation. The chick DRGn were immunolabeled with an anti-chick N-CAM monoclonal antibody, and the length of the single longest neurite per neuron was measured. In random fields $>50$ neurons were scored on each of the multiple sections in three separate experiments. Data represent the means and SEM expressed as a percentage of the untreated control value. ${ }^{*} p \leq 0.005 ;{ }^{* *} p<0.0001$. Statistical significance was determined by Student's $t$ test.

presence of phenanthroline, confirming that the degradation resulted from metalloproteinase activity (lane 3). MMP-2 degradation of NIF was attributed exclusively to core protein proteolysis because $\left[{ }^{35} \mathrm{~S}\right]$ glycosaminoglycans remained associated with polypeptide fragments. In contrast, the $\left[{ }^{35} \mathrm{~S}\right]$ glycosaminoglycan (and thus autoradiographic tag) of NIF was stripped from the core protein by chondroitinase ABC digestion (lane 4). Western immunoblotting of NIF treated with chondroitinase revealed a core protein of $\sim 150-200 \mathrm{kDa}$ (see Zuo et al., 1998).

\section{DISCUSSION}

Numerous studies indicate that certain extracellular proteoglycans are inhibitory molecules that, at high concentration relative to growth-promoting signals, may regulate or repress axonal growth. We previously characterized a neurite-inhibiting CSPG, named NIF, produced by cultured rat RN22 schwannoma and Schwann cells (Muir et al., 1989a). NIF reversibly binds to and inhibits the neurite-promoting activity of laminin. NIF-laminin complexes isolated from culture medium fail to promote neuritic growth when they are substratum-bound. However, both NIF and laminin are recovered in active forms by dissociative fractionation of NIF-laminin complexes. Additionally, the neurite-promoting activity of laminin is restored by degrading substratum-bound NIF-laminin complexes with chondroitinase (Zuo et al., 1998). NIF activity is expressed only by the intact proteoglycan, and its inhibitory activity is abolished by cleavage of its chondroitin

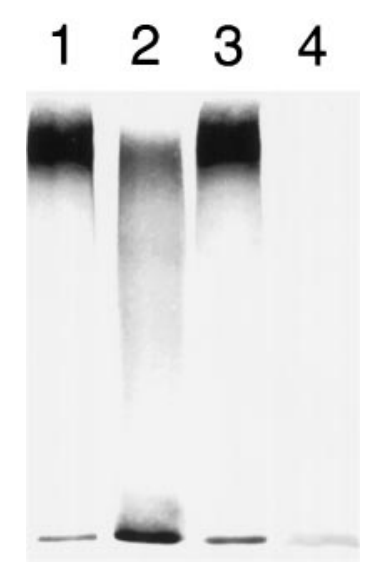

Figure 6. Autoradiographic analysis of proteolytic degradation of ${ }^{35}$ S]NIF by MMP-2. Metabolically radiosulfate-labeled NIF was incubated with MMP-2 before SDS-PAGE under reducing conditions. Intact $\left[{ }^{35} \mathrm{~S}\right]$ NIF $(3 \mu \mathrm{g})$ appeared on autoradiograms as a broad band with a molecular mass of $\approx 400 \mathrm{kDa}$ (lane 1). The electrophoretic mobility of $\left[{ }^{35} \mathrm{~S}\right] \mathrm{NIF}(3 \mu \mathrm{g})$ was shifted after proteolysis by MMP-2 $(20 \mathrm{ng}$ in $10 \mu \mathrm{l}$; lane 2). Inclusion of phenanthroline (1 mM) prevented the degradation of $\left[{ }^{35} \mathrm{~S}\right]$ NIF (lane 3$) .\left[{ }^{35} \mathrm{~S}\right]$ chondroitin sulfate chains of $\left[{ }^{35} \mathrm{~S}\right] \mathrm{NIF}$ were cleaved by chondroitinase $\mathrm{ABC}(0.02 \mathrm{U}$ in $10 \mu \mathrm{l})$, resulting in the complete loss of autoradiographic profile (lane 4).

sulfate chains by chondroitinase or by limited proteolysis of its core protein. On the basis of the premise that a NIF-laminin substratum can be deinhibited enzymatically, we set out to determine whether neurons secrete enzymes that inactivate NIF in vitro and in peripheral nerve tissue.

We first discovered that embryonic DRGn grown on a NIFlaminin substratum for extended periods failed to grow neurites in media containing the metalloproteinase inhibitor cysteine. In medium without cysteine, neurites initially were delayed but gradually elongated on the NIF-laminin. Because it was known to us that DRGn (treated with NGF) express the metalloproteinase MMP-2 (Muir, 1994), experiments were performed to determine whether MMP-2 can degrade NIF and deinhibit NIFlaminin substrata. Principal findings from our study include the following: (1) Neuritic growth by embryonic DRGn on a synthetic NIF-laminin substratum and on normal nerve tissue sections is dependent mainly on a metalloproteinase. (2) MMP-2 is secreted by DRGn and is transported to the growing tips of regenerating neurites. (3) MMP-2 degrades and inactivates NIF but does not affect the neurite-promoting activity of laminin. (4) Neuritic growth by DRGn cultured on nerve tissue sections is increased markedly by first treating the nerve sections with MMP-2, and the deinhibiting effect of MMP-2 is equal to and nonadditive with that of chondroitinase. (5) Laminin activity is masked in normal adult nerve, and treatment of nerve tissue sections with MMP-2 or chondroitinase unmasks the neurite-promoting activity of endoneurial laminin. These findings support the conclusion that MMP-2 expression provides a mechanism for growth cones to deinhibit the growth-promoting properties of laminin residing in the endoneurial basal lamina.

The culture of neurons on tissue sections (cryoculture) has been used to study mechanisms of neuritic growth and to better understand the neurite-promoting status of peripheral and central nervous tissues. Neurite outgrowth on tissue sections is clearly directed by the organization of tissues in the underlying substrata. Growth cones have an exquisite ability to probe their 
substratum and decipher cues that influence their direction of growth. Experimentally, the pattern of neuritic growth on tissue sections reveals the functional state of molecular signals within the extracellular environment. Furthermore, cryoculture offers the unique opportunity to examine the neurite-promoting properties of normal tissues devoid of degenerative and inflammatory elements. By using sections of normal nerve, this bioassay also can help to assess determinants of neuronal differentiation and stabilization. Moreover, it is then possible to study alterations that occur during the transition from a steady-state to a regenerative one. In nerve injury this transition may have important consequences for the success of axonal regeneration and functional recovery. Langley and Anderson (1904) first reported that transected axons do not regenerate along a normal nerve. More recently, the repressive status of normal nerve has been confirmed in the cryoculture model wherein adult DRG axons fail to grow neurites on sections of normal adult nerve (Bedi et al., 1992). These findings suggest that, although rich in laminin, Schwann cell surfaces and their associated basal lamina in normal nerve fail to support and actively may inhibit axonal growth. This repressive disposition may be responsible for the initial delay in axonal regeneration that occurs after nerve injury (see Tapia et al., 1995). Although axons sprout numerous collaterals within hours of injury, significant elongation is delayed initially and then accelerates to reach a constant rate within $3 \mathrm{~d}$ (Wyrwicka, 1950). Regenerating axon sprouts arise rapidly from the first node of Ranvier proximal to the site of injury and immediately interface with established tissue components that have not yet undergone significant Wallerian degeneration (for review, see Fu and Gordon, 1997). The transition of the endoneurial basal lamina from an inhibited state to a promoting one is likely an important event governing the onset of axonal elongation. Extracellular matrices are relatively stable structures, and modifications of basal lamina composition are not likely to occur rapidly. On the other hand, whereas axon sprouting and immediate elongation occur without requiring the cell body to participate, the ability to overcome inhibitory signals may be transcription/translation-dependent. The requirement for axonal transport of regulatory proteins to the site of nerve injury would incur a considerable delay. In this regard, we previously have reported that the expression of MMP-2 by cultured DRGn is induced by NGF (Muir, 1994). NGF levels are very low in normal sciatic nerve. However, local NGF levels rapidly increase near the site of nerve injury (Heumann et al., 1987). Although it presently is unknown whether MMP-2 is upregulated in response to NGF in vivo, it is interesting to speculate that proteolytic mechanisms are an important part of the regenerative responses to NGF.

MMP-2 is present at the growing tip of neurites, and it is now known that MMP-2 is activated and can reside on the cell surface (Sato et al., 1996). Therefore, axonal growth may involve spatial and temporal regulation of ECM degradation at the cell surface. This suggests that the growing axon may invoke a process of focalized proteolysis similar to that proposed for the pericellular degradation brought to bear at the leading edge of migrating and invading cells during wound healing and tumor metastasis (Basbaum and Werb, 1996). On the basis of past and present findings, we propose that MMP-2 at the growing tip of axons may have two interrelated functions: one involving degradation of collagenous matrix barriers (see Muir, 1994) and another more selective process of degrading inhibitory CSPG. MMP-2 action at the growth cone may represent a discrete and focal mechanism by which neurons alter their environment in the distal nerve.

Differences in the growth responses of embryonic and adult DRGn on nerve tissue sections have been reported (Bedi et al., 1992; Agius and Cochard, 1998). It has been postulated that the age-dependent decline in axonal growth may be attributed to a relative insensitivity of embryonic neurons to growth inhibitors. This explanation clearly does not apply to the response of embryonic DRGn to CSPG in vitro. Furthermore, our findings indicate that growth by embryonic DRGn, like that reported for adult neurons, also is inhibited significantly by CSPG within the endoneurium of normal adult nerve sections. Although other intrinsic mechanisms may influence the growth of embryonic and adult neurons on nerve sections, our studies raise the possibility that the expression of enzymes such as MMP-2 enables embryonic DRGn to overcome the inhibition by CSPG, which otherwise represents an insurmountable barrier to axonal growth. MMP-2 expression and activity are highly regulated, and further experiments are required to determine whether adult DRGn fail to inactivate inhibitory CSPG under the conditions of these assays or if the mechanism of deinhibition by MMP-2 can be elicited by growth factors other than NGF. It is interesting that various neurotrophins influence the growth of DRGn on different tissue substrata and that, in contrast to previous findings with NGF alone, mature DRGn treated with a combination of NGF, NT-3, and BDNF extended neurites on sections of normal adult sciatic nerve (Tuttle and Matthew, 1995; Golding et al., 1996).

Using confocal microscopy to discriminate the association of neurites with discrete aspects of the basal lamina, Agius and Cochard (1998) observed that embryonic DRGn neurites did not obtain access to the laminin-rich inner structures of endoneurial tubes in normal nerve sections. Accordingly, the moderate neuritic growth observed in this condition was attributed to components other than laminin. Our findings using function-blocking laminin antibodies confirm previous reports that growth on normal nerve sections is not mediated by laminin. The degenerative process that occurs in nerve distal to the site of injury has a significant impact on the ability of nerve to support axonal regeneration and, furthermore, may involve an ability of growth cones to access the laminin-rich aspects of the endoneurial basal laminin (Bedi et al., 1992; Danielsen et al., 1995; Agius and Cochard, 1998). Similarly, we found that the treatment of normal nerve sections with MMP-2 markedly increases the ability of nerve tissue to support neuritic growth and that this increased occurred in response to laminin because it was blocked by laminin antibodies.

Several in vitro and in vivo models demonstrate that the entire distal nerve has an increased ability to support axonal growth after Wallerian degeneration (Bedi et al., 1992; Danielsen et al., 1995). After injury, Schwann cells become activated and participate in the remodeling of the endoneurial basal lamina. Degradation and remodeling of extracellular matrices are certainly important aspects of the regenerative process, and MMP-2 is expressed not only by regenerating neurons but also by Schwann cells and invading macrophages (Muir, 1995; Yamada et al., 1995; La Fleur et al., 1996). Accordingly, an additional supportive role for these cells in the regenerative process may include the general conversion of the endoneurial basal lamina from a repressive to a facilitative substratum for axonal growth. We propose that MMP-2 plays a key role in this fundamental process. It very well may be that the proteolytic competence of regenerating nervous tissues and resident neurons determines the extent and course of 
axonal regeneration. Studying the expression of matrix-degrading enzymes in response to injury and the proteolytic vulnerability of inhibitory components also might help to explain the contrasting regenerative responses of injured peripheral and central nervous tissues at various developmental stages.

\section{REFERENCES}

Agius E, Cochard P (1998) Comparison of neurite outgrowth induced by intact and injured sciatic nerves: a confocal and functional analysis. J Neurosci 18:328-338.

Anton ES, Sandrock AJ, Matthew WD (1994) Merosin promotes neurite growth and Schwann cell migration in vitro and nerve regeneration in vivo: evidence using an antibody to merosin, ARM-1. Dev Biol 164:133-146.

Basbaum CB, Werb Z (1996) Focalized proteolysis: spatial and temporal regulation of extracellular matrix degradation at the cell surface. Curr Opin Cell Biol 8:731-738.

Bedi KS, Winter J, Berry M, Cohen J (1992) Adult rat dorsal root ganglion neurons extend neurites on predegenerated but not on normal peripheral nerves in vitro. Eur J Neurosci 4:193-200.

Bottenstein JE, Sato GH (1979) Growth of a rat neuroblastoma cell line in serum-free supplemented medium. Proc Natl Acad Sci USA 76:514-517.

Brittis PA, Canning DR, Silver J (1992) Chondroitin sulfate as a regulator of neuronal patterning in the retina. Science 255:733-736.

Carbonetto S, Evans D, Cochard P (1987) Nerve fiber growth in culture on tissue substrata from central and peripheral nervous systems. J Neurosci 7:610-620.

Chantry A, Gregson N, Glynn P (1992) Degradation of myelin basic protein by a membrane-associated metalloprotease: neural distribution of the enzyme. Neurochem Res 17:861-867.

Danielsen N, Kerns JM, Holmquist B, Zhao Q, Lundborg G, Kanje M (1995) Predegeneration enhances regeneration into acellular nerve grafts. Brain Res 681:105-108.

DiStefano PS, Chelsea DM, Schick CM, McKelvy JF (1993) Involvement of a metalloprotease in low-affinity nerve growth factor receptor truncation: inhibition of truncation in vitro and in vivo. J Neurosci 13:2405-2414.

Engvall E, Davis GE, Dickerson K, Ruoslahti E, Varon S, Manthorpe M (1986) Mapping of domains in human laminin using monoclonal antibodies: localization of the neurite-promoting site. J Cell Biol 103:2457-2465.

Faissner A, Steindler D (1995) Boundaries and inhibitory molecules in developing neural tissues. Glia 13:233-254.

Fambrough D, Pan D, Rubin GM, Goodman CS (1996) The cell surface metalloprotease/disintegrin Kuzbanian is required for axonal extension in Drosophila. Proc Natl Acad Sci USA 93:13233-13238.

Fridman R, Fuerst TR, Bird RE, Hoyhtya M, Oelkuct M, Kraus S, Komarek D, Liotta LA, Berman ML, Stetler-Stevenson WG (1992) Domain structure of human $72 \mathrm{kDa}$ gelatinase/type IV collagenase. Characterization of proteolytic activity and identification of the tissue inhibitor of metalloproteinase-2 (TIMP-2) binding regions. J Biol Chem 267:15398-15405.

Fu SY, Gordon T (1997) The cellular and molecular basis of peripheral nerve regeneration. Mol Neurobiol 14:67-116.

Giannelli G, Falk-Marzillier J, Schraldi O, Stetler-Stevenson WG, Quaranta V (1997) Induction of cell migration by matrix metalloproteinase-2 cleavage of laminin-5. Science 277:225-228.

Giannini C, Dyck PJ (1990) The fate of Schwann cell basement membranes in permanently transected nerves. J Neuropathol Exp Neurol 49:550-563.

Golding JP, Shewan D, Berry M, Cohen J (1996) An in vitro model of the rat dorsal root entry zone reveals developmental changes in the extent of sensory axon growth into the spinal cord. Mol Cell Neurosci 7:191-203.

Grobelny D, Poncz L, Galardy RE (1992) Inhibition of human skin fibroblast collagenase, thermolsin, and Pseudomonas aeruginosa elastase by peptide hydroxamic acids. Biochemistry 31:7152-7154.

Hayden SM, Seeds NW (1996) Modulated expression of plasminogen activator system components in cultured cells from dissociated mouse dorsal root ganglia. J Neurosci 16:2307-2317.

Heumann R, Korsching S, Bandtlow C, Thoenen H (1987) Changes of nerve growth factor synthesis in nonneuronal cells in response to sciatic nerve transection. J Cell Biol 104:1623-1631.
Ide C, Tohyama K, Yokota R, Nitatori T, Onodera S (1983) Schwann cell basal lamina and nerve regeneration. Brain Res 288:61-75.

Kolodkin AL (1996) Growth cones and the cues that repel them. Trends Neurosci 19:507-513.

Kuecherer-Ehret A, Graeber MB, Edgar D, Thoenen H, Kreutzberg GW (1990) Immunoelectron microscopic localization of laminin in normal and regenerating mouse sciatic nerve. J Neurocytol 19:101-109.

La Fleur M, Underwood JL, Rappolee DA, Werb Z (1996) Basement membrane and repair of injury to peripheral nerve: defining a potential role for macrophages, matrix metalloproteinases, and tissue inhibitor of metalloproteinases-1. J Exp Med 184:2311-2326.

Langley JN, Anderson HK (1904) The union of different kinds of nerve fibres. J Physiol (Lond) 31:365-391.

Lowe-Krentz LJ, Keller JM (1984) Disulfide-bonded aggregates of heparan sulfate proteoglycans. Biochemistry 23:2621-2627.

Machida CM, Rodland KD, Matrisian L, Magun BE, Ciment G (1989) NGF induction of the gene encoding the protease transin accompanies neuronal differentiation in PC12 cells. Neuron 2:1587-1596.

Manthorpe M, Engvall E, Ruoslahti E, Longo FM, Davis GE, Varon S (1983) Laminin promotes neuritic regeneration from cultured peripheral and central neurons. J Cell Biol 97:1882-1890.

Matrisian LM (1992) The matrix-degrading metalloproteinases. BioEssays 14:455-463.

McGuire PG, Seeds NW (1990) Degradation of underlying extracellular matrix by sensory neurons during neurite outgrowth. Neuron 4:633-642.

Monard D (1988) Cell-derived proteases and protease inhibitors as regulators of neurite outgrowth. Trends Neurosci 11:541-544.

Muir D (1994) Metalloproteinase-dependent neurite outgrowth within a synthetic extracellular matrix is induced by nerve growth factor. Exp Cell Res 210:243-252.

Muir D (1995) Differences in proliferation and invasion by normal, transformed, and NF1 Schwann cell cultures are influenced by matrix metalloproteinase expression. Clin Exp Metastasis 13:303-314.

Muir D, Engvall E, Varon S, Manthorpe M (1989a) Schwannoma cellderived inhibitor of the neurite-promoting activity of laminin. J Cell Biol 109:2353-2362.

Muir D, Gennrich C, Varon S, Manthorpe M (1989b) Rat sciatic nerve Schwann cell microcultures: responses to mitogens and production of trophic and neurite-promoting factors. Neurochem Res 14:1003-1012.

Nordstrom LA, Lochner J, Yeung W, Ciment G (1995) The metalloproteinase stromelysin-1 (transin) mediates PC12 cell growth cone invasiveness through basal laminae. Mol Cell Neurosci 6:56-68.

Oakley RA, Tosney KW (1991) Peanut agglutinin and chondroitin-6sulfate are molecular markers for tissues that act as barriers to axon advance in the avian embryo. Dev Biol 147:187-206.

Pindzola RR, Doller C, Silver J (1993) Putative inhibitory extracellular matrix molecules at the dorsal root entry zone of the spinal cord during development and after root and sciatic nerve lesions. Dev Biol 156:34-48.

Pittman RN, Buettner HM (1989) Degradation of extracellular matrix by neuronal proteases. Dev Neurosci 11:361-375.

Pittman RN, Williams AG (1988) Neurite penetration into collagen gels requires $\mathrm{Ca}^{2+}$-dependent metalloproteinase activity. Dev Neurosci 11:41-51.

Ray JM, Stetler-Stevenson WG (1995) Gelatinase A activity directly modulates melanoma cell adhesion and spreading. EMBO J 14:908-917.

Salonen V, Peltonen J, Roytta M, Virtanen I (1987) Laminin in traumatized peripheral nerve: basement membrane changes during degeneration and regeneration. J Neurocytol 16:713-720.

Sandrock AW, Matthew WD (1987) Identification of a peripheral nerve neurite growth-promoting activity by development and use of an in vitro bioassay. Proc Natl Acad Sci USA 84:6934-6938.

Satinsky D, Pepe FA, Liu CN (1964) The neurilemma cell in peripheral nerve degeneration and regeneration. Exp Neurol 9:441-451.

Sato H, Takino T, Kinoshita T, Imai K, Okada Y, Stetler-Stevenson WG, Seiki M (1996) Cell surface binding and activation of gelatinase A induced by expression of membrane-type-1-matrix metalloproteinase (MT1-MMP). FEBS Lett 385:238-240.

Snow DM, Watanabe M, Letourneau PC, Silver J (1991) A chondroitin sulfate proteoglycan may influence the direction of retinal ganglion cell outgrowth. Development 113:1473-1485.

Tapia M, Inestrosa NC, Alvarez J (1995) Early axonal regeneration: repression by Schwann cells and a protease? Exp Neurol 131:124-132. 
Tona A, Perides G, Rahemtulla F, Dahl D (1993) Extracellular matrixin regenerating rat sciatic nerve: a comparative study on the localization of laminin, hyaluronic acid, and chondroitin sulfate proteoglycans, including versican. J Histochem Cytochem 41:593-599.

Tuttle R, Matthew WD (1995) Neurotrophins affect the pattern of DRG neurite growth in a bioassay that presents a choice of CNS and PNS substrates. Development 121:1301-1309.

Watanabe M, Frelinger ALD, Rutishauser U (1986) Topography of $\mathrm{N}$-CAM structural and functional determinants. I. Classification of monoclonal antibody epitopes. J Cell Biol 103:1721-1727.

Wilhelm SM, Collier IE, Kronberger A, Eisen AZ, Marmer BL, Grant GA, Bauer EA, Goldberg GI (1987) Human skin fibroblast stromely- sin: structure, glycosylation, substrate specificity, and differential expression in normal and tumorigenic cells. Proc Natl Acad Sci USA 84:6725-6729.

Wyrwicka W (1950) On the rate of regeneration of the rat sciatic nerve in the white mouse. Acta Biol Exp (Warsz) 15:147-153.

Yamada T, Miyazaki K, Koshikawa N, Takahashi M, Akatsu H, Yamamoto T (1995) Selective localization of gelatinase A, an enzyme degrading beta-amyloid protein, in white matter microglia and in Schwann cells. Acta Neuropathol (Berl) 89:199-203.

Zuo J, Hernandez YJ, Muir D (1998) Chondroitin sulfate proteoglycan with neurite-inhibiting activity is up-regulated following peripheral nerve injury. J Neurobiol 34:41-54. 